\title{
Delayed Development of Adult-Generated Granule Cells in Dentate Gyrus
}

\author{
Linda S. Overstreet-Wadiche, AeSoon L. Bensen, and Gary L. Westbrook \\ Vollum Institute, L474, Oregon Health \& Science University, Portland, Oregon 97239
}

\begin{abstract}
A substantial fraction of adult-generated granule cells in the dentate gyrus survive and integrate into the existing neuronal network. These newborn neurons must navigate the environment of the adult brain, a setting that is presumably less optimized for neuronal maturation compared with that in the developing brain. We used EGFP (enhanced green fluorescent protein) expression in newborn granule cells to compare the maturation of adult-generated granule cells to those generated in neonates. Labeled newborn granule cells had indistinguishable physiological properties in adults and neonates, indicating they were at the same functional stage. However, the maturation of adult-generated granule cells was slower than neonatal-generated granule cells. Depolarizing GABAergic network activity and transcription factor activation were reduced in adults relative to neonates, suggesting a role for neural activity in the maturation of newborn granule cells. Consistent with this idea, maturation was altered in mice lacking the GABA synthetic enzyme GAD65 (glutamic acid decarboxylase 65). Together, these results provide evidence that activity-dependent processes in the local environment influence the maturation of newborn granule cells.
\end{abstract}

Key words: granule cell; depolarizing GABA; development; giant depolarizing potential; activity dependent; neural stem cell; neurogenesis; dentate gyrus; bromodeoxyuridine; hippocampus; GAD65

\section{Introduction}

Neurogenesis is a well established feature of the adult dentate gyrus. However, to participate in hippocampal-dependent behaviors, newborn neurons must functionally integrate into the preexisting circuit. How newly generated cells interact with their environment, particularly a mature neuronal network, is a general problem in stem cell biology. Knowledge of these interactions is critical for exploiting the therapeutic potential of stem cells (Goldman, 2005). Neurogenesis in the dentate gyrus provides a model system to explore the influence of the microenvironment on neural stem cell fate. Recent work with hippocampal progenitors demonstrates that the environment in vitro determines the phenotype of newborn cells (Song et al., 2002; Deisseroth et al., 2004; Shen et al., 2004). The different environment of the adult and neonatal brain could also influence how newborn neurons integrate in vivo.

Activity is one environmental factor that could influence integration. Activity-dependent maturation of neurons and synapses is well established (Cohen-Cory, 2002; Wong and Ghosh, 2002). Many developing networks display spontaneous patterns of intrinsic activity that promote neural development and connectivity (Katz and Shatz, 1996; Ben-Ari, 2001; Yu et al., 2004). Likewise, activity-dependent processes have been implicated in

Received July 5, 2005; revised Jan. 13, 2006; accepted Jan. 14, 2006.

This work was supported by National Institutes of Health Grant NS-26494 (G.L.W.). We thank members of the Westbrook laboratory for comments and suggestions during this project.

Correspondence should be addressed to Linda S. Overstreet-Wadiche, Vollum Institute, L474, Oregon Health \& Science University, 3181 Southwest Sam Jackson Park Road, Portland, OR 97239. E-mail: overstre@ohsu.edu. DOI:10.1523/JNEUROSCI.4111-05.2006

Copyright $\odot 2006$ Society for Neuroscience $\quad 0270-6474 / 06 / 262326-09 \$ 15.00 / 0$ the maturation of adult neural progenitors (Deisseroth et al., 2004; Saghatelyan et al., 2005; Tozuka et al., 2005). In the adult dentate gyrus, depolarizing GABAergic input to progenitors is a mechanism that could underlie activity-dependent neural differentiation (Tozuka et al., 2005). Although depolarizing network activity in the neonate hippocampus is dramatically elevated compared with the adult hippocampus (Ben-Ari, 2001), it is unclear whether this difference influences the maturation of newborn granule cells.

To assess the impact of the adult environment on neuronal maturation, we compared the development of newborn granule cells in adults with their development in neonates. We used enhanced green fluorescent protein (EGFP) expression in proopiomelanocortin (POMC)-EGFP transgenic mice to identify newborn granule cells (Overstreet et al., 2004). In adult mice, EGFP-labeled granule cells have immature neuronal morphology and physiology, and they express immature markers such as PSAnCAM (polysialylated neural cell adhesion molecule). We found that EGFP is expressed in newborn granule cells at a similar functional stage in neonates. However, the timing of EGFP and neuronal-specific nuclear protein (NeuN) expression indicated that this functional stage was delayed in adults. This was confirmed by demonstrating that the excitable properties of 2-weekold granule cells in adults were less mature than similar-aged granule cells in neonates. The network activity in neonates suggested that depolarizing GABAergic activity in surrounding cells can promote faster maturation of newborn cells. Accordingly, EGFP expression was delayed in neonate mice when this pattern of activity was reduced by genetic deletion of the GABA synthetic enzyme glutamic acid decarboxylase 65 (GAD65). These results 
support the idea that activity in the environment of newborn granule cells is an important regulator of maturation.

\section{Materials and Methods}

The generation of POMC-EGFP mice was described previously (Overstreet et al., 2004). We used heterozygous -13/+8POMC-EGFP transgenic mice, maintained by outbreeding homozygous males with wildtype C57BL/6J females. GAD65 ${ }^{-1-}$ mice were provided by K. Obata (RIKEN, Wako, Japan) (Asada et al., 1996) and crossed with POMCEGFP heterozygotes to generate GAD $65^{+/+}$and GAD $65^{-/-} / \mathrm{POMC}-$ EGFP mice. All mice were maintained in a C57BL/6J background. All animal procedures followed the Guide for the Care and Use of Laboratory Animals, United States Public Health Service, and were approved by the Oregon Health \& Science University Institutional Animal Care and Use Committee.

Electrophysiology. Horizontal slices from the hippocampus were incubated in a solution containing the following (in $\mathrm{mM}$ ): $125 \mathrm{NaCl}, 25$ $\mathrm{NaHCO}_{3}, 2.5 \mathrm{KCl}, 1.25 \mathrm{NaH}_{2} \mathrm{PO}_{4}, 0.5 \mathrm{CaCl}_{2}, 2.5 \mathrm{MgCl}_{2}$, and 25 D-glucose, bubbled with $95 \% \mathrm{O}_{2} / 5 \% \mathrm{CO}_{2}$. We used a similar extracellular solution for whole-cell recordings except that $\mathrm{CaCl}_{2}$ was increased to 2.0 $\mathrm{mm}$ and $\mathrm{MgCl}_{2}$ was reduced to $1.0 \mathrm{~mm}$. Patch pipettes were filled with the following (in mM): $150 \mathrm{KCl}, 10 \mathrm{HEPES}, 4 \mathrm{Mg}_{2} \mathrm{ATP}, 0.5 \mathrm{NaGTP}, 10$ phosphocreatine, and $0.2 \%$ biocytin or $135 \mathrm{~K}$-gluconate, $15 \mathrm{KCl}, 5 \mathrm{NaCl}, 0.5$ EGTA, 10 HEPES, $2 \mathrm{Mg}_{2}$ ATP, and $0.2 \%$ biocytin, $\mathrm{pH} 7.3$ and $310 \mathrm{mOsm}$, 4-8 $\mathrm{M} \Omega$ resistance. Differential interference contrast and fluorescent images were combined (PIX/2; MicroImage Video Systems, Boyertown, $\mathrm{PA})$ for simultaneous viewing of $\mathrm{EGFP}^{+}$and unlabeled cells. Series resistance ( $8-25 \mathrm{M} \Omega$, compensated $50-80 \%)$ was monitored and experiments discarded if substantial changes were observed. Currents were filtered at $2 \mathrm{kHz}$ and sampled at $10 \mathrm{kHz}$ (Axopatch 200B; Molecular Devices, Union City, CA). Unless noted, recordings were done at $22^{\circ} \mathrm{C}$. Action potential amplitudes were measured from threshold. Voltages were not corrected for junction potentials. Membrane time constants were determined by fitting a single exponential function to membrane responses to small hyperpolarizing current injections. Spontaneous activity was recorded in $15 \mathrm{~min}$ epochs and analyzed off-line using the template-matching protocol in Axograph 4.9. Synaptic currents analogous to "giant depolarizing potentials" (GDPs) were defined by an amplitude more than five times the average spontaneous event in each cell. The high input resistance of newborn granule cells made it likely that current leak through the pipette seal contributed to variability and underestimates of the actual input resistance. Data are expressed as mean \pm SEM, and unless noted, paired or unpaired $t$ tests were used to determine statistical significance at the $p<0.05$ level. All drugs and chemicals were obtained from Sigma (St. Louis, MO) or Tocris (Ellisville, MO).

$\mathrm{Ca}^{2+}$ imaging. Slices from postnatal day $4(\mathrm{P} 4)$ to $\mathrm{P} 7$ neonates were incubated for $1-2 \mathrm{~h}$ in X-rhod-1 (AM) $(4-8 \mu \mathrm{M}$; Invitrogen, Eugene, OR) and then washed for $1-3 \mathrm{~h}$ in extracellular solution. Multiple X-rhod-1-labeled cells were imaged in a single field $(63 \times$ objective; 0.9 numerical aperture; Zeiss, Oberkochen, Germany) with a QLC100 confocal scanning head (Yokogawa, Tokyo, Japan) mounted on a Zeiss FS-2 microscope using $488 \mathrm{~nm}$ (EGFP) and $568 \mathrm{~nm}$ (X-rhod-1) laser illumination. $\mathrm{Ca}^{2+}$ signals and EGFP fluorescence were detected with a XR/ Mega10 ICCD camera (Stanford Photonics, Stanford, CA) controlled by QED software (Media Cybernetics, Silver Spring, MD). $\mathrm{Ca}^{2+}$ signals were imaged continuously in 3-4 min epochs (568 nm; 4-5 Hz; $35^{\circ}$ ) interleaved with averaged images acquired at 488 and $568 \mathrm{~nm}$ to identify EGFP- and X-rhod-1-labeled cells. The average pixel intensities in regions of interest surrounding cell bodies in the granule cell layer were normalized $(\Delta F / F)$ using Axograph 4.9. EGFP and X-rhod-1 images were overlaid in Photoshop. Cell bodies with high basal $\mathrm{Ca}^{2+}$ signals did not show spontaneous transients and were not counted.

5-Bromo-2'-deoxyuridine labeling and immunohistochemistry. Adult POMC-EGFP transgenic mice (age 12-16 weeks) received four 5 -bromo-2'-deoxyuridine (BrdU) injections $(300 \mathrm{mg} / \mathrm{kg}$ in $0.9 \%$ saline, i.p.; Sigma) at $2 \mathrm{~h}$ intervals. Pregnant female mice were injected on embryonic days $16-19$. We used a lower dose of BrdU to reduce the neurotoxic effects of BrdU in neonates that lack a blood-brain barrier (150 $\mathrm{mg} / \mathrm{kg}$ in $0.9 \%$ saline, i.p.). At days $1,3,6,8,10,11$ or $12,14,16,24$, and
30 after injection, adult mice ( $>20 \mathrm{~d}$ ) were anesthetized with 2,2,2tribromoethanol (Avertin; Aldrich, Milwaukee, WI) and transcardially perfused with $4 \%$ paraformaldehyde in PBS. Brains were removed and postfixed overnight. Neonate and juvenile mice $(<30 \mathrm{~d})$ were anesthetized with halothane, and the brains were quickly removed, blocked, and fixed in $4 \%$ paraformaldehyde for $2 \mathrm{~d}$. Horizontal sections through the hippocampus $(50 \mu \mathrm{m})$ were cut on a vibratome and stored at $-20^{\circ} \mathrm{C}$ in cryoprotecting buffer (30\% ethylene glycol, $20 \%$ glycerin, and $0.05 \mathrm{M}$ PBS). BrdU immunohistochemistry was performed simultaneously on sections from all intervals. Every sixth section through each hippocampus was processed. Free-floating sections were washed twice in KPBS, incubated in $2 \mathrm{~N} \mathrm{HCl}\left(30 \mathrm{~min}\right.$ at $\left.37^{\circ} \mathrm{C}\right)$, and rinsed in 0.1 borate buffer, $\mathrm{pH} 8.5$ (10 $\mathrm{min})$. Sections were incubated in KPBS $/ 0.4 \%$ Triton $\mathrm{X}-100 / 5 \%$ normal goat serum for $30 \mathrm{~min}$ followed by overnight incubation with primary anti-BrdU antibody (monoclonal rat; 1:200; Oxford Biotechnology, Oxfordshire, UK). After rinsing, sections were incubated for $1 \mathrm{~h}$ in Texas Red-conjugated goat anti-rat IgG (1:200; Jackson ImmunoResearch, West Grove, PA). Sections were then incubated for $1 \mathrm{~h}$ in AlexaFluor 488 rabbit anti-GFP IgG (1:500; Invitrogen). For BrdU/ NeuN colocalization, sections were incubated sequentially in mouse anti-NeuN (overnight; 1:1000; Chemicon, Temecula, CA), sheep antiBrdU (overnight; 1:500; Abcam, Cambridge, MA) followed by goat antimouse AlexaFluor 488 (2 h; 1:200; Invitrogen) and donkey anti-sheep AlexaFluor 647 (2 h; 1:200; Invitrogen). For NeuroD and phosphorylated cAMP response element-binding protein (pCREB) immunoreactivity, sections were incubated in $0.4 \% \mathrm{PBS} / 0.4 \%$ Triton X-100/5\% normal donkey serum (1 h), followed by goat anti-NeuroD1 (overnight; 1:100; Santa Cruz Biotechnology, Santa Cruz, CA) or anti-pCREB (overnight; 1:200; Santa Cruz Biotechnology). Sections were then incubated with donkey anti-goat AlexaFluor 647 (2 h; 1:200), followed by rabbit antiGFP AlexaFluor 488. All protocols included control reactions in which primary antibodies were omitted. Sections were mounted with Prolong Antifade (Invitrogen) and imaged with fluorescent or confocal microscopes.

After recordings, slices were fixed with $4 \%$ paraformaldehyde overnight, washed, and incubated in Cy5-conjugated streptavidin $(1 \mu \mathrm{g} / \mathrm{ml}$; Jackson ImmunoResearch) in PBS/0.4\% Triton X-100. Only a fraction of filled EGFP-labeled cells were recovered. For morphometric measurements, we reconstructed biocytin-filled cells or EGFP-labeled cells with maximum $z$-projections of confocal stacks (0.5-1.0 $\mu$ m intervals) using ImageJ. EGFP-labeled cells that were relatively isolated from neighboring labeled cells were selected for reconstructions. Total dendritic length was measured with NeuronJ (Meijering et al., 2004). For BrdU/EGFP colocalization, cell counts were performed blind to the experimental condition, and results were confirmed by a second blinded investigator. We were interested in relative numbers, so no corrections were made for section thickness or cell diameter. Based on a slice thickness of $50 \mu \mathrm{m}$ and cell diameter of $<10 \mu \mathrm{m}$, our counts may overestimate the actual numbers by $\sim 15 \%$, although the use of every sixth section reduces the error (Guillery and Herrup, 1997). The number of $\mathrm{BrdU}^{+}$nuclei positioned within or immediately adjacent to the granule cell layer $(>50$ cells per mouse), the number of $\mathrm{EGFP}^{+}$cells ( $>400$ cells per mouse), and the number of cells that colocalized BrdU and EGFP were counted. For other colocalization experiments, errors were reduced by counting cells in single optical sections. The number of cells per field was measured by propidium iodide or Sytox orange nucleic acid stain (Invitrogen).

\section{Results}

\section{EGFP labels newborn granule cells in adults and neonates}

We used EGFP expression in the dentate gyrus of POMC-EGFP transgenic mice to distinguish newborn (labeled) from more mature (unlabeled) granule cells. Transient EGFP expression serves as a marker of newborn granule cells at an early developmental stage (Overstreet et al., 2004). Although the number of labeled newborn cells declines with increasing age (Overstreet et al., 2004), individual cells had similar morphological characteristics regardless of the age of the animal. Labeled cell bodies were small and located near the subgranular zone with a primary dendrite 
that branched and terminated within the inner molecular layer (Fig. 1). Labeled cells had mossy fiber axons that terminated in stratum lucidem, but they lacked mature mossy fiber boutons. Newborn granule cells had similar excitable properties at all ages, characterized by small, broad action potentials, and high input resistance ( $\mathrm{Ta}$ ble 1). Newborn granule cells in adults and neonates also have similar synaptic connectivity. Although they lack glutamatergic synaptic input, newborn granule cells have depolarized GABAergic responses and GABAergic synaptic currents with slow decay phases in adults and neonates (Overstreet-Wadiche et al., 2005). Newborn granule cells in adults and neonates also expressed the same developmental markers (see below). Although we cannot rule out the possibility that subtle intrinsic differences exist between newborn granule cells in adults and neonates, these results indicate that EGFP-labeled cells are at a similar functional stage regardless of the age of the animal.

\section{Delayed development of adult generated granule cells}

We next used BrdU labeling to compare when granule cells achieve the stage marked by EGFP expression (Fig. 2a). There was significant colocalization between BrdU and EGFP (Fig. $2 b, c$ ), but the maximal degree and the temporal pattern of colocalization differed between neonates and adults (Fig. $2 d$ ). In adults, most $\mathrm{BrdU}^{+}$ cells were located near the inner granule cell layer. Colabeling between BrdU and EGFP
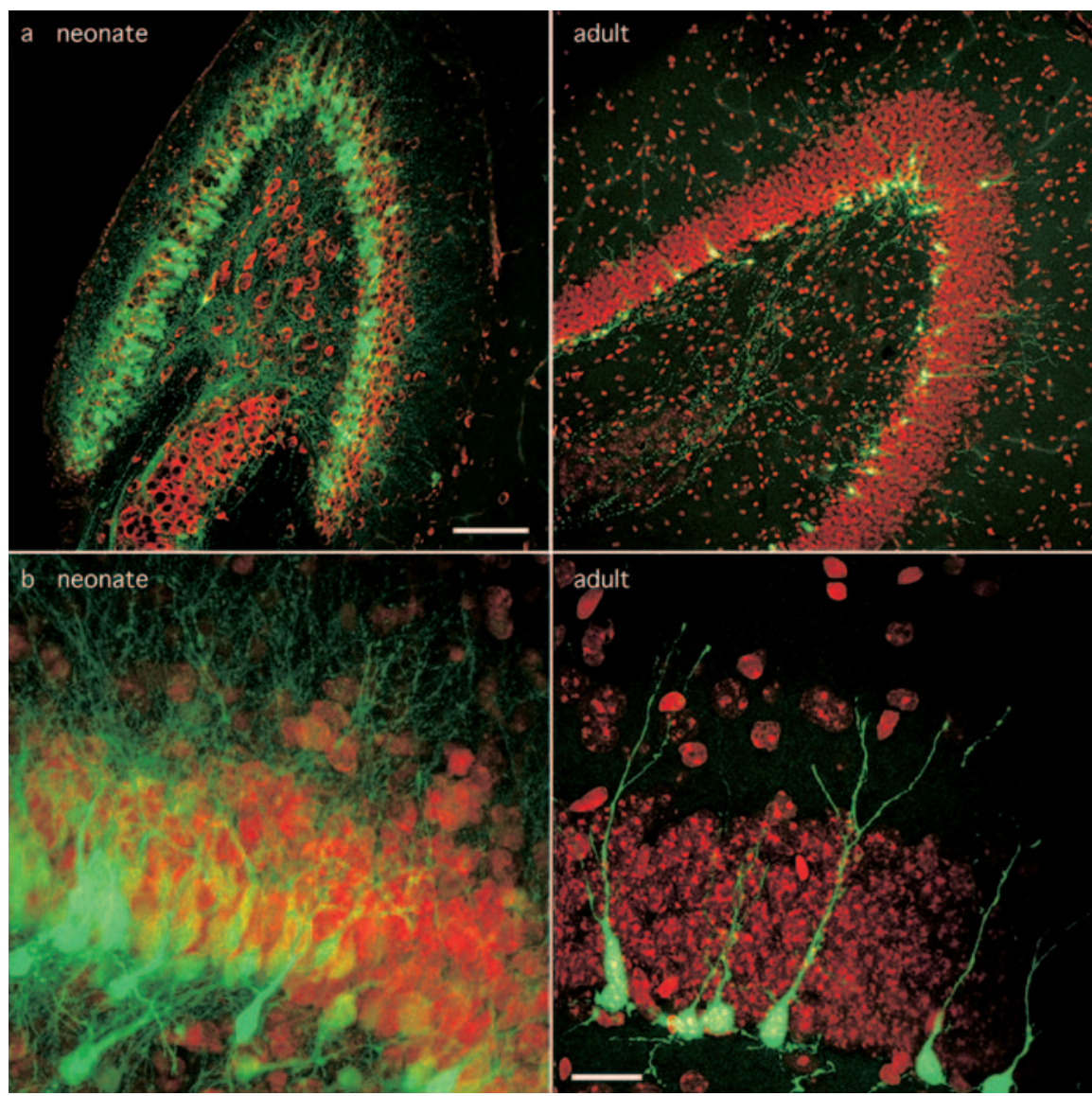

Figure 1. EGFP labels newborn granule cells in adults and neonates. $\boldsymbol{a}$, Confocal images of EGFP expression in the dentate gyrus from a P10 mouse (left) and a 4-month-old mouse (right). Each image is a maximum intensity z-projection of sections at $1 \mu \mathrm{m}$. Cell bodies are stained with propidium iodide (red). Scale bar, $100 \mu \mathrm{m}$. Although the number of newborn cells decreased with age, individual cells had the same immature properties (Table 1). $\boldsymbol{b}$, Higher magnification images from a P7 mouse (left) and a 4-month-old mouse (right) show the similar morphology of labeled newborn cells. The dendrites of newborn cells extended into the inner molecular layer and had similar total length (Table 1), although the primary dendrite appeared shorter in neonates. Scale bar, $20 \mu \mathrm{m}$.

peaked at $12 \mathrm{~d}$ and declined gradually over

the next 2 weeks (Fig. $2 b, d$ ). In the neonatal hippocampus, $\mathrm{BrdU}^{+}$ cells were found throughout the cell layers, consistent with neurogenesis of pyramidal cells and interneurons. Importantly, colabeling between BrdU and EGFP in newborn granule cells peaked earlier and declined more rapidly than in adults, an effect that was most apparent by normalizing each profile to the peak colabeling (Fig. $2 d$, right). The delayed expression of EGFP in adults suggested that adult-generated granule cells developed at a slower rate.

If granule cells develop more slowly in adults compared with neonates, other developmental markers, such as NeuN, should also reflect the different temporal pattern. Thus, we compared BrdU and NeuN colocalization at 12 and $30 \mathrm{~d}$ after BrdU incorporation. Indeed, $12 \mathrm{~d}$ after BrdU incorporation, $66 \pm 3.0 \%$ of $\mathrm{BrdU}^{+}$cells expressed NeuN in neonates compared with only $47 \pm 4.8 \%$ in adults $(n=3$ each; $p<0.05)$ (Fig. 3$)$. As expected, the percentage of $\mathrm{BrdU}^{+}$cells that expressed NeuN increased between 12 and $30 \mathrm{~d}$ in both neonates $(87 \pm 0.6 \% ; p<0.001)$ and adults $(79 \pm 2.3 ; p<0.001)$. However, at $30 \mathrm{~d}$, the percentage was not different between adults and neonates, suggesting that delayed maturation accounted for the difference at $12 \mathrm{~d}$, rather than a difference in phenotype. Interestingly, BrdU and NeuN colocalization is even further delayed in 2-year-old rats compared with young adult rats (Rao et al., 2005), suggesting that newborn granule cell development may be further slowed in aged animals.
In rodents, granule cell neurogenesis occurs over a prolonged time window, beginning at embryonic days 10-14 and peaking after birth (Angevine, 1965; Schlessinger et al., 1975). Hence, at postnatal days 5-7, the "oldest" granule cells are in the same postmitotic age range as EGFP-labeled cells in adults. However, random unlabeled granule cells in $\mathrm{P} 5-\mathrm{P} 7$ mice had more mature excitable and morphological properties than EGFP-labeled granule cells in adults. Specifically, unlabeled granule cells had lower input resistances, faster membrane time constants, and larger action potentials with faster kinetics (Fig. 4, Table 1). Morphological measurements of biocytin-filled cells revealed that the total dendrite length of unlabeled cells at P5-P7 (687 $\pm 113 \mu \mathrm{m}$; $n=7)$ was greater than newborn cells in adults $(241 \pm 16 \mu \mathrm{m}$; $n=8)$. Although we cannot know the exact age of any individual labeled or unlabeled cell, the relatively mature properties of unlabeled granule cells in neonates were never observed in EGFPlabeled cells in adults. Together, these results indicate that adultgenerated granule cells develop more slowly than granule cells generated during the neonatal period. In addition, the comparison between unlabeled granule cells in neonates and adults showed that the amplitude and duration of action potentials had reached mature values in neonates. However, the smaller $\mathrm{Na}^{+}$ current and total dendritic length indicates that unlabeled granule cells in neonates are not yet fully mature. 
Table 1. Properties of newborn granule cells in adults and neonates

\begin{tabular}{|c|c|c|c|c|c|c|c|}
\hline & $\operatorname{IR}(G \Omega)$ & $\tau_{\mathrm{m}}(\mathrm{ms})$ & AP amp (mV) & AP half-width (ms) & $I_{\mathrm{Na}}{ }^{+}(\mathrm{nA})$ & TDL ( $\mu \mathrm{m})$ & sPSC frequency $(\mathrm{Hz})$ \\
\hline \multicolumn{8}{|l|}{ Adults } \\
\hline Newborn & $8.0 \pm 2.0(8)^{*}$ & $106 \pm 16(8)^{*}$ & $35 \pm 5(8)^{*}$ & $9.3 \pm 2.4(8)^{*}$ & $0.3 \pm 0.1(7)^{*}$ & $241 \pm 16(8)^{*}$ & $0.04 \pm 0.02(7)^{*}$ \\
\hline Unlabeled & $0.5 \pm 0.2(6)$ & $30 \pm 4.4(6)$ & $88 \pm 5(6)$ & $1.4 \pm 0.1(6)$ & $6.3 \pm 1.1(5)$ & $2061 \pm 184(6)$ & $7.0 \pm 0.7(5)$ \\
\hline \multicolumn{8}{|l|}{ Neonates } \\
\hline Newborn & $4.7 \pm 1.7(6)^{*}$ & $77 \pm 15(6)^{*}$ & $33 \pm 5(6)^{*}$ & $6.8 \pm 0.7(6)^{*}$ & $0.1 \pm 0.1(6)^{*}$ & $189 \pm 26(8)^{*}$ & $0.06 \pm 0.03(11)^{*}$ \\
\hline Unlabeled & $0.9 \pm 0.2(9)$ & $43 \pm 3.3(9)$ & $90 \pm 3(9)$ & $1.5 \pm 0.1(9)$ & $1.4 \pm 0.3(6)$ & $687 \pm 113(7)$ & $6.5 \pm 1.9(5)$ \\
\hline
\end{tabular}

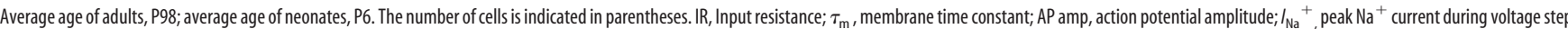
from -70 to $-30 \mathrm{mV}$; TDL, total dendrite length. Spontaneous postsynaptic current (sPSC) frequency includes the high-frequency bursts in neonates.

*Significantly different from unlabeled granule cells at $p \leq 0.05$. None of the values were different between newborn cells in adults and neonates.

a
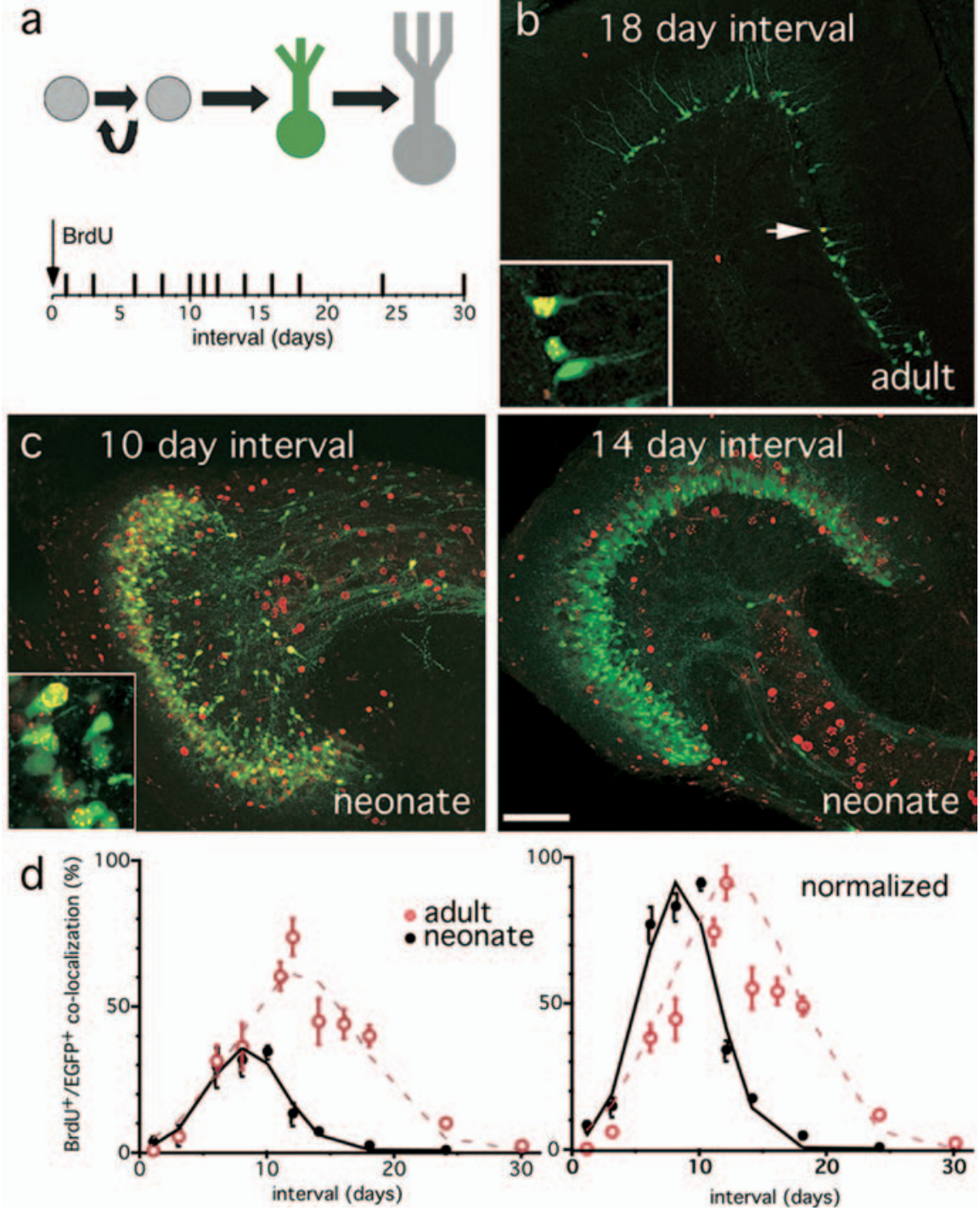

Figure 2. Accelerated EGFP expression in newborn neurons in neonates. $\boldsymbol{a}$, Granule cell development includes a period of transient EGFP expression. We used a pulse-chase experiment to determine the time course of EGFP expression. BrdU was administered to adult and embryonic day 16-19 POMC-EGFP mice on day 0 to label S-phase cells. Mice were then perfused 1-30 d later. $\boldsymbol{b}$, In adults, $18 \mathrm{~d}$ after BrdU administration, most BrdU-labeled cells were located near the subgranular zone and many were colocalized with EGFP. The inset shows colabeled cells (arrow) at a higher magnification. c, In neonates, BrdU administration labeled all layers of the hippocampus. Colabeling of BrdU with EGFP in the granule cell layer peaked at $10 \mathrm{~d}$ (left panel) and almost disappeared by $14 \mathrm{~d}$ (right panel). Scale bar: (in c) $\boldsymbol{b}, \boldsymbol{c}, 50 \mu \mathrm{m}$. $\boldsymbol{d}$, The percentage of BrdU ${ }^{+}$cells that colocalized with EGFP revealed the temporal expression profile of EGFP (left; $n=3-5$ mice/interval). EGFP expression in adults was delayed relative to that in neonates. The lines indicate Gaussian fits to the data points. In the right panel, data were normalized to the maximum degree of colabeling. Error bars indicate SEM.
Different patterns of network activity in adults and neonates

Network activity in the neonate could promote neuronal maturation. Networks in the neonatal visual system (Katz and Shatz, 1996), motor system (Khazipov et al., 2004), olfactory bulb (Yu et al., 2004), and cortex (Adelsberger et al., 2005) all display spontaneous patterns of intrinsic activity critical for their normal development. Likewise, the neonatal hippocampus displays characteristic spontaneous activity, so-called GDPs (Ben-Ari et al., 1989). These locally synchronized network discharges propagate through the entire hippocampus (Leinekugel et al., 1998) during a restricted period of development (Leinekugel et al., 2002). Thus, they are well positioned to promote activitydependent maturation in the neonate (Ben-Ari, 2001).

To determine whether network activity patterns differed in the neonatal and adult dentate gyrus, we recorded from granule cells in slices from neonatal (postnatal days $4-7)$ or adult (>3 month) mice. EGFP-labeled newborn granule cells in neonatal mice had a low frequency of spontaneous GABAergic synaptic events similar to that in adults (Fig. 5, Table 1). High-frequency bursts of activity were present in only 2 of 11 EGFP-labeled cells in neonates (data not shown), likely reflecting their low synaptic connectivity (Overstreet-Wadiche et al., 2005). However, most unlabeled granule cells in neonate slices showed prominent bursts of high-frequency spontaneous activity (5 of 7 cells) that lasted hundreds of milliseconds (Hollrigel et al., 1998). The bursts were superimposed on a constant background of individual synaptic events $(0.7 \pm 0.4 \mathrm{~Hz} ; 68 \pm$ $10 \mathrm{pA}$ ) (Fig. $5 a$, asterisks). The events within the bursts as well as the background activity had kinetics consistent with GABAergic IPSCs and were dramatically reduced by the $\mathrm{GABA}_{\mathrm{A}}$ receptor antagonist 6-imino-3-(4methoxyphenyl)-1(6H)-pyridazinebutanoic hydrobromide (SR95531) $(n=4)$. Although mainly GABAergic, the spontaneous events were depolarizing because of the 
a
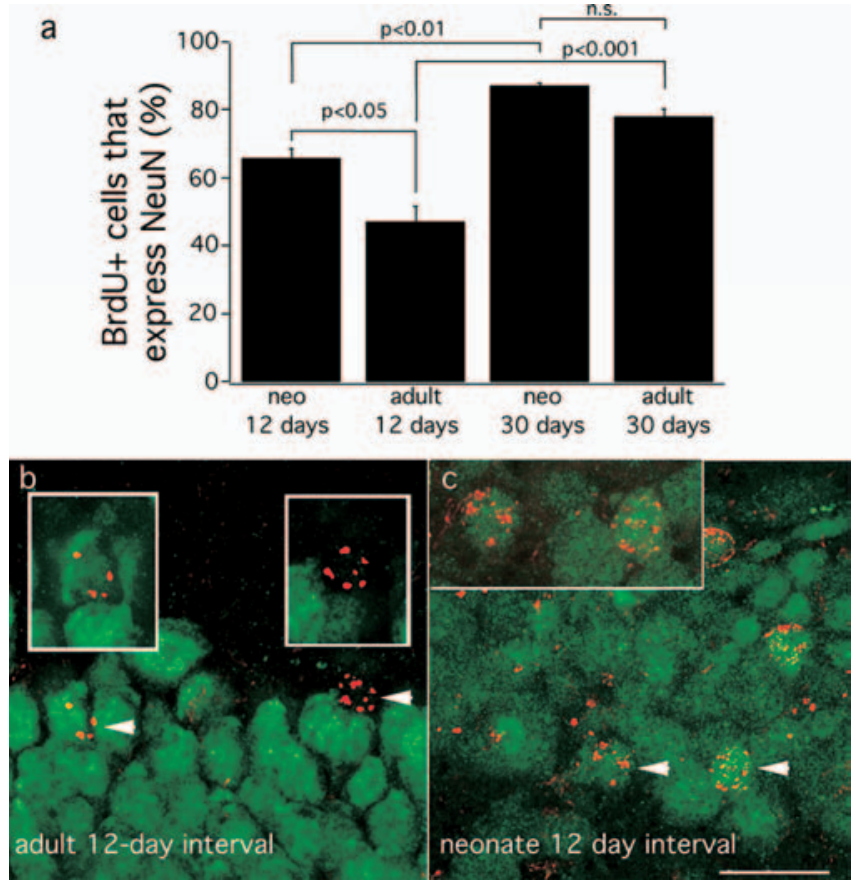

Figure 3. Different temporal expression of NeuN in neonates and adults. $\boldsymbol{a}$, Twelve days after BrdU incorporation, more BrdU ${ }^{+}$cells expressed NeuN in neonates compared with adults. After $30 \mathrm{~d}$, colocalization increased in both adults and neonates, but was not different between adults and neonates (ANOVA with Tukey-Kramer multiple comparisons). Error bars indicate SEM. $\boldsymbol{b}, \boldsymbol{c}$, Examples of BrdU/NeuN immunoreactivity in adult and neonate mice. Images are z-projections of 16 confocal stacks at $1 \mu \mathrm{m}$ intervals. In adults, BrdU ${ }^{+}$cells were located exclusively near the subgranular zone. The arrows indicate cells that are shown in the insets. In neonates, $\mathrm{BrdU}^{+}$ cells were located the throughout the granule cell layer. Scale bar, $20 \mu \mathrm{m}$.

\section{a}

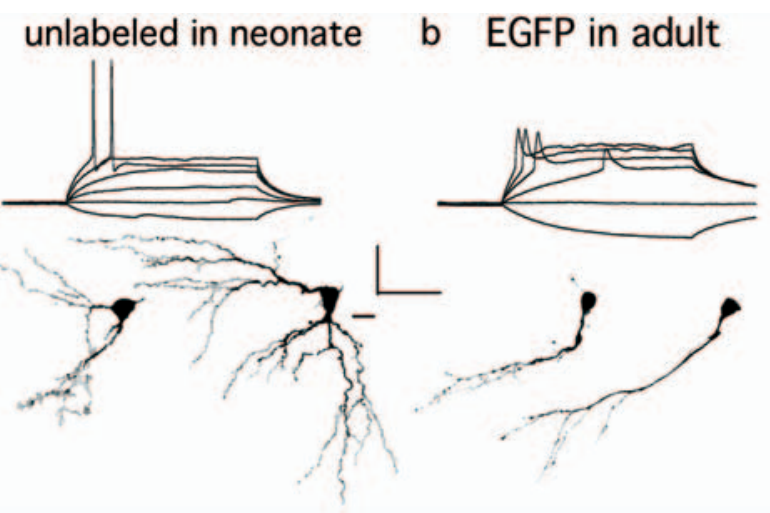

Figure 4. Granule cells at the same postmitotic age have more mature properties in neonates. $\boldsymbol{a}, \boldsymbol{b}$, Granule cells (unlabeled) in neonates are $\sim 2$ weeks postmitotic or younger (i.e., similar in age to EGFP-labeled cells in adult mice). However, their dendritic morphology and excitability were more mature (Table 1). The top traces show typical voltage responses to current injections ( 20 and $5 \mathrm{pA} \mathrm{steps,} \mathrm{respectively).} \mathrm{Calibration:} 50 \mathrm{mV}, 50 \mathrm{~ms}$. Reconstructions from biocytin-filled cells and EGFP-labeled cells were traced from $z$-series projections at $1 \mu \mathrm{m}$ intervals. Scale bar, $10 \mu \mathrm{m}$.

depolarized chloride equilibrium potential in immature granule cells (Hollrigel et al., 1998). At near physiological temperature (30$35^{\circ} \mathrm{C}$ ), bursts of high-frequency events were even more prominent, and included clusters that could last tens of seconds $(n=7)$ (data not shown). This patterned activity, analogous to GDPs observed in other hippocampal subregions (Leinekugel et al., 1997), was associated with $\mathrm{Ca}^{2+}$ transients. In slices from neonate mice that were loaded with the membrane-permeable $\mathrm{Ca}^{2+}$ indicator X-rhod-1 a $a_{\text {neonate, EGFP-labeled granule cell }}$

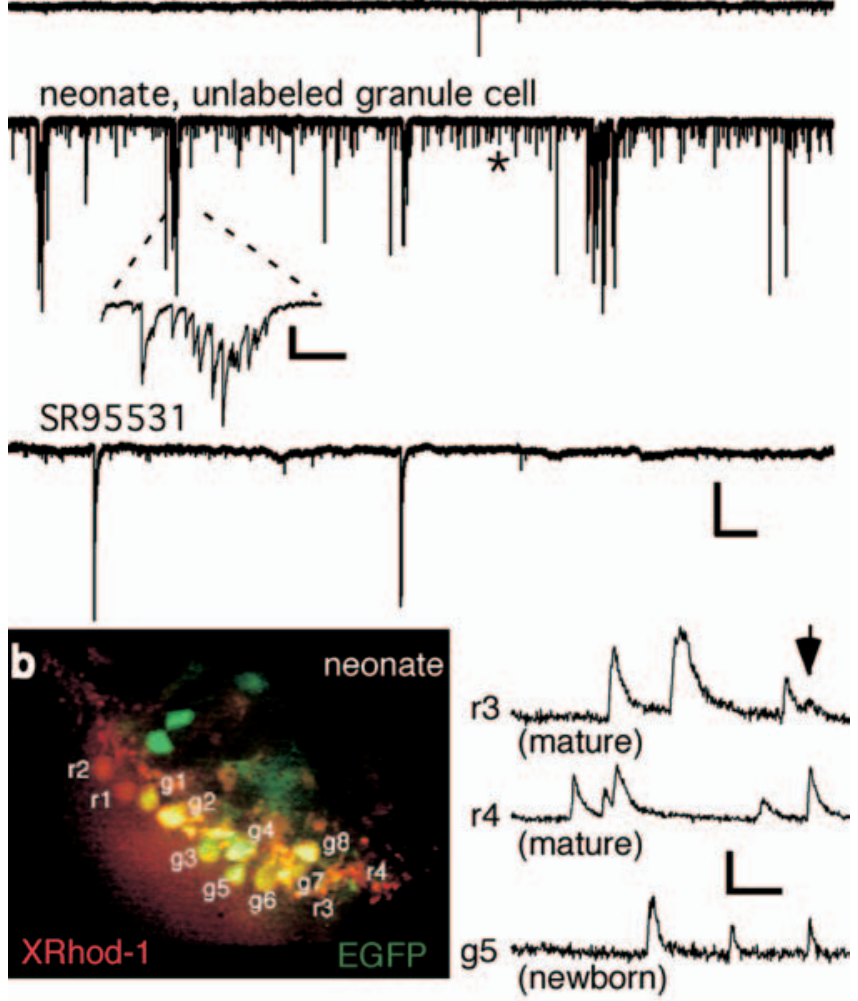

C adult, mature granule cell

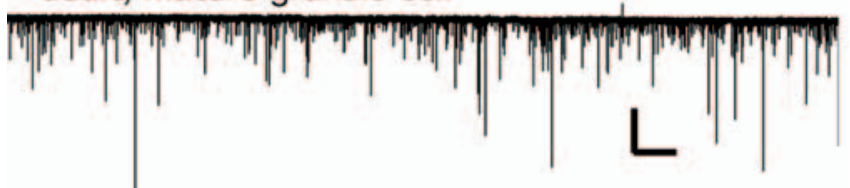

Figure 5. Spontaneous synaptic activity patterns in neonates and adults. $\boldsymbol{a}$, EGFP-labeled granule cells from neonatal mice had a low frequency of spontaneous GABAergic synaptic events, similar to that seen in adults (Table 1). Unlabeled granule cells from neonates exhibited patterned spontaneous activity analogous to giant depolarizing potentials in other hippocampal subregions (Ben-Ari, 2001). Activity consisted of bursts of spontaneous events (inset) interspersed on a background of smaller individual spontaneous events (asterisk). Calibration: 100 pA, 10 s; inset, 100 pA, $500 \mathrm{~ms}$. Spontaneous activity was dramatically reduced by SR95531, indicating it was mediated by $\mathrm{GABA}_{A}$ receptors (KCl-based intracellular solution). $\boldsymbol{b}$, Spontaneous network activity in neonates generated $\mathrm{Ca}^{2+}$ transients. Confocal image (left) of granule cells in an acute slice from a neonatal POMC-EGFP mouse after incubation with the membranepermeable $\mathrm{Ca}^{2+}$ indicator $\mathrm{X}$-rhod-1. Many newborn cells loaded with the indicator are yellow, indicating both EGFP and X-rhod-1 fluorescence. Some newborn cells were not loaded with indicator (green), and mature granule cells loaded with X-rhod-1 are red. Examples of spontaneous $\mathrm{Ca}^{2+}$ transients (right) imaged in the numbered cells. $\mathrm{r} 3$ and $\mathrm{r} 4$ are mature granule cells, and $\mathrm{g} 6$ is a newborn cell. Imaging was performed at $35^{\circ} \mathrm{C}$. The arrowhead indicates synchronized events in multiple cells. Calibration: 50\% F/F, $30 \mathrm{~s}$. c, In contrast to neonates, mature granule cells in adults did not have patterned spontaneous activity. Although there was a high frequency of GABAergic synaptic events, the hyperpolarized reversal potential for GABA-evoked currents in mature cells would inhibit depolarizing activity. Calibration: 400 pA, 10 s.

(AM) (Fig. 5b, left), robust spontaneous $\mathrm{Ca}^{2+}$ transients were present in both unlabeled and newborn granule cells (Fig. 2b, right). We observed spontaneous transients during 3-4 min epochs in $59 \pm$ $8 \%$ of newborn cells and $60 \pm 8 \%$ of unlabeled cells ( $n=44$ and 34 cells, respectively). Spontaneous $\mathrm{Ca}^{2+}$ transients were completely blocked by SR95531 in newborn granule cells $(n=9)$, but not in more mature cells $(n=8)$. Thus, whole-cell recordings and $\mathrm{Ca}^{2+}$ imaging demonstrate that patterns of spontaneous activity analogous to GDPs are present in the neonatal mouse dentate gyrus. 

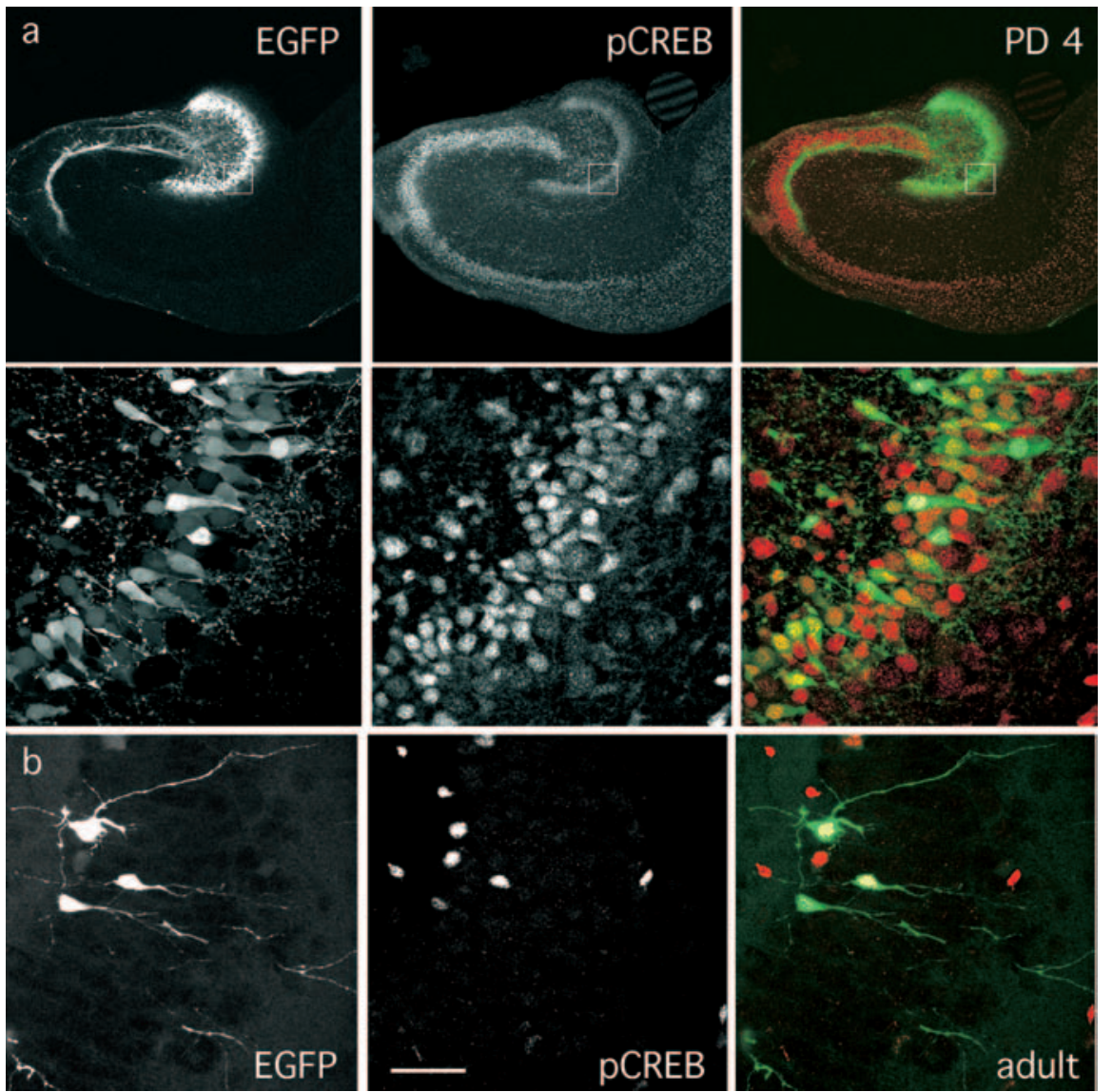

Figure 6. Different molecular environment in neonates and adults. $\boldsymbol{a}$, There was robust pCREB expression in all layers of the hippocampus in sections from neonatal brains. Low-magnification images show EGFP-labeled mossy fibers in stratum lucidem and migrating granule cells (left panel). The boxed region is enlarged in the middle row of panels, showing that many $p C R E B$ and colabeled cells were present throughout the granule cell layer. PD 4, Postnatal day 4. $\boldsymbol{b}, \mathrm{pCREB}$ immunoreactivity was much lower in the granule cell layer in sections from adults. However, similar to neonates, the majority of newborn cells expressed pCREB. Scale bar, $50 \mu \mathrm{m}$. Colabeling between pCREB and the nuclear stain Sytox orange revealed that the majority of all granule cells expressed pCREB in neonates; however, only a small fraction of granule cells expressed pCREB in adults, most of which were newborn neurons. In neonates, newborn granule cells made up $28 \pm 7 \%$ of total cells within the granule cell layer, whereas in adults $2.7 \pm 0.2 \%$ of cells were newborn.

In contrast, we never observed patterned bursts of highfrequency spontaneous activity in granule cells from adults. This is consistent with previous findings that GDPs in other subregions of the hippocampus disappear during the second postnatal week (BenAri, 2001; Leinekugel et al., 2002). Although the frequency of spontaneous activity in mature granule cells was high and predominately mediated by GABAergic events $(7.0 \pm 0.7 \mathrm{~Hz} ; n=5)$ (Fig. $5 c)$, the chloride equilibrium potential is more hyperpolarized and GABAergic responses counteract excitatory input (Staley and Mody, 1992). Together, these results indicate that spontaneous network activity in neonates and adults is dramatically different. In neonates, newborn neurons reside in a network with robust bursts of depolarizing activity that generate calcium transients, whereas this patterned activity is absent in adults.

\section{Activity-dependent transcription factors in adults and neonates}

Different activity patterns in the environment of newborn granule cells could alter the expression of many molecules that influence neuronal development. We thus compared the expression of two activity-regulated transcription factors that have been implicated in activity-dependent neuronal growth, CREB (Redmond et al., 2002) and NeuroD (Gaudilliere et al., 2004). Activated CREB, as detected by pCREB immunoreactivity, was strongly expressed in all layers of the hippocampus in neonates (Fig. 6). Most newborn granule cells had robust expression of pCREB (71 $\pm 2 \% ; n=3$ mice) and colabeling with a nuclear stain revealed that more than one-half of all cells in the granule cell layer were also pCREB positive $(60 \pm 6 \%$; $n=$ $3)$. However, there was a different expression pattern in adult mice. Although most newborn cells in adults also expressed pCREB $(70 \pm 7 \% ; n=6)$, immunoreactivity in surrounding cells was low $(5 \pm 2 \%$; $n=$ 6). A similar expression pattern was seen with NeuroD (supplemental Fig. 1, available at www.jneurosci.org as supplemental material). EGFP-labeled granule cells showed NeuroD immunoreactivity in both neonates and adults. However, in neonates, newborn cells were surrounded by more mature granule cells that also expressed NeuroD. Thus, the pattern of transcription factor activation paralleled the pattern of activity in adults and neonates, suggesting that newborn neurons in neonates are exposed to an environment enriched in activity-dependent gene expression.

\section{Genetic deletion of GAD65 alters granule cell maturation}

We next tested the idea that activitydependent mechanisms contribute to accelerated granule cell maturation in neonates. Because the characteristic neonatal patterns of activity are predominantly generated by GABAergic mechanisms (Fig. 5) (Ben-Ari et al., 2001), we crossed POMC-EGFP mice with mice lacking one of the GABA synthetic enzymes, GAD65 (Asada et al., 1996). GAD65 is responsible for producing vesicular GABA (Soghomonian and Martin, 1998). Genetic deletion of GAD65 reduces hippocampal GABA content (Hensch et al., 1998) and GABA synaptic release (Tian et al., 1999). As illustrated in Figure 7, the frequency of GDPs recorded in unlabeled granule cells was reduced in GAD65 ${ }^{-1-}$ neonatal mice $(2.3 \pm 0.9$ per minute) compared with GAD65 ${ }^{+/+}$littermates $(7.3 \pm 1.9$ per minute; $n=6$ cells each; $p=0.01)$. However, the amplitude and frequency of the smaller individual synaptic events were not significantly affected. If GDPs promote maturation in neonates, we expected a prolonged temporal profile of BrdU/EGFP colocalization in neonate GAD $65^{-1-}$ mice. We measured colocalization at the interval with the greatest difference between adults and neonates (16 d) (Fig. 2). In this situation, delayed maturation would appear as an increase in BrdU colocalization. Consistent with the idea that GABAergic network activity accelerates granule cell maturation, BrdU/EGFP colocalization in GAD65 $5^{-1-}$ mice was increased by more than twofold compared with wild-type littermates (218\% of control; $n=3$ mice each; $p<0.005)$. The number of EGFP- and BrdU-labeled cells per field was not significantly altered ( $115 \%$ of control and $91 \%$ of control, respectively). Furthermore, the morphology of EGFP-labeled cells appeared 
unaltered, suggesting that only their rate of maturation was affected.

During neuronal maturation, GABAergic responses shift from depolarizing to hyperpolarizing. Thus, in neonate dentate gyrus, the net effect of GABA is excitatory, whereas in adults the net effect of GABA is inhibitory. Indeed, adult GAD $65^{-1-}$ mice have a reduced threshold for seizure induction (Asada et al., 1996) and display spontaneous seizures (Kash et al., 1997). Interestingly, labeled granule cells had a different appearance in adults, with larger cell bodies and dendrites that extended through the molecular layer (supplemental Fig. 2, available at www.jneurosci. org as supplemental material). There were also greater numbers of labeled cells. This appearance was similar to that observed after pilocarpine-induced seizures, when EGFP-labeled granule cell integration is dramatically accelerated (L. S. OverstreetWadiche, unpublished observation).

\section{Discussion}

It is generally acknowledged that adult neurogenesis occurs in a relatively hostile environment (Kempermann et al., 2004; Rakic, 2004). To date, most experimental attention has been directed at the neurogenic potential of the permissive microenvironment in the subgranular zone where neural progenitors proliferate. Yet participation of adult-generated neurons in hippocampal function requires that newborn neurons leave this niche and navigate within the mature circuit with its well established connectivity. The characteristic patterns of spontaneous activity and depolarizing GABAergic responses in developing systems suggest that such activity may enhance neural growth and integration (Ben-Ari, 2001). Direct depolarization by GABA can promote neural differentiation from adult progenitors (Tozuka et al., 2005). Indirect depolarization resulting from network activity may also influence differentiation (Deisseroth et al., 2004). Regardless of the specific mechanisms, our results demonstrate that adultgenerated neurons develop more slowly than granule cells in neonates and suggest that activity-dependent processes are involved. This further implies that activity can influence the maturation, as well as proliferation and differentiation, of newborn neurons.

\section{Tracking newborn neurons with POMC-EGFP}

The morphology, excitable properties, and expression of various markers indicate that EGFP-labeled granule cells are immature postmitotic neurons (Overstreet et al., 2004). In the classification scheme of Alvarez-Buylla and colleagues (Seri et al., 2001, 2004), EGFP-labeled cells likely correspond to late D2 and D3 cells. In the nomenclature of Kempermann and colleagues, EGPF-labeled cells likely correspond to early stage 5 postmitotic immature granule cells (Kempermann et al., 2004). Although the factors responsible for expression of POMC-EGFP in newborn granule cells are unknown (Overstreet et al., 2004), the high degree of colocalization between BrdU and EGFP suggests that all granule cells are transiently labeled. Thus, EGFP expression in the dentate of POMC-EGFP mice provides a selective marker for newborn granule cells at an early developmental stage.

Although EGFP-labeled newborn granule cells express functional AMPA and NMDA receptors, they only receive GABAergic synaptic input (Overstreet-Wadiche et al., 2005). The GABAergic input to newborn cells has immature characteristics including slow decays and depolarized reversal potentials. Consistent with a trophic role of GABA during development (Owens and Kriegstein, 2002), depolarizing GABAergic responses in neonates contributed to calcium signals in both unlabeled granule cells as well as labeled newborn granule cells. Spontaneous $\mathrm{Ca}^{2+}$ transients in newborn granule cells that lacked prominent burst activity (GDPs) suggest that unitary GABAergic synaptic events are sufficient to generate $\mathrm{Ca}^{2+}$ signaling. Furthermore, depolarizing GABAergic responses in newborn neurons after perforant path input develops could facilitate NMDA receptor activation and thereby promote NMDA receptor-dependent plasticity (Pavlov et al., 2004).

Delayed development of adult-generated granule cells

Although various immunohistochemical markers have been correlated with the postmitotic age of adult-generated granule cells (Seki, 2002; Brown et al., 2003), this approach does not allow direct correlation with cell function. The homogeneous properties of EGFP-labeled cells indicate EGFP expression labels cells at a specific early functional stage. Although we cannot know the exact age of any individual cell, in adults this functional stage occurred between 3 and $24 \mathrm{~d}$ after BrdU incorporation $(>1 \%$ BrdU/EGFP colabeling). In neonates, it occurred between 1 and $18 \mathrm{~d}$ after BrdU incorporation. The average postmitotic age of EGFP-labeled granule cells in adults was $\sim 12 \mathrm{~d}$, whereas in neo- 
nates it was $\sim 8 \mathrm{~d}$. One caveat of BrdU incorporation is that subsequent generations of newborn cells can be detected (Dayer et al., 2003). However, the developmental delay we observed is greater than the temporal spread that results from the intrinsic limits of all BrdU labeling. From these results, we can infer that most adult-generated newborn granule cells lack glutamatergic perforant path input for the first 2 weeks of their existence. This timing of maturation is consistent with recent studies using viral labeling to track the granule cell development (Esposito et al., 2005; Zhao et al., 2006). Thus, activity in most adult-generated granule cells is limited to intrinsic hippocampal activity for a period of weeks.

We interpret the broader window of EGFP expression in adults as attributable to a prolonged expression of EGFP in individual cells. In principle, this could also reflect less synchronous development across the population of adult-generated granule cells. However, the latter possibility is unlikely, because this would reduce the peak colabeling of BrdU and EGFP in adults. In fact, peak colabeling in adults was greater than in neonates. Thus, we conclude that the stage of development marked by EGFP expression is prolonged in adults. This is also consistent with the reduced dendritic length and spine density of adult newborn granule cells identified by retroviral labeling (Zhao et al., 2006). Furthermore, accelerated development of granule cells in neonates is consistent with their relatively mature functional characteristics (Table 1), including perforant path input (Liu et al., 2000; Ye et al., 2005), by the end of the first postnatal week.

\section{Modulation of granule cell development}

Clearly, all of the conditions of the neonate environment are not absolutely essential for granule cell development, because some fraction of adult-generated granule cells can integrate into the mature circuit and become indistinguishable from their more mature counterparts (van Praag et al., 2002). However, factors such as depolarizing network activity are well positioned to facilitate neural development. Direct depolarization of progenitors promotes neuronal differentiation via NeuroD expression (Deisseroth et al., 2004; Tozuka et al., 2005); thus enhanced GABAergic depolarization of progenitors in neonates could contribute to age-dependent accelerated maturation. We did not detect a difference in spontaneous GABAergic input to EGFP-labeled cells in neonates and adults. Rather, activity and gene expression in surrounding unlabeled granule cells was dramatically different. Network activity in surrounding cells could modify the molecular environment of newborn neurons. Depolarization regulates many transcription factors involved in growth and synaptogenesis, including CREB. pCREB expression was widespread in neonatal hippocampus, suggesting that spontaneous depolarizing activity could drive CREB-mediated BDNF expression (Shieh et al., 1998; Tao et al., 1998) and release (McAllister et al., 1996; Horch, 2004) from granule cells that surround newborn neurons. Consistent with this idea, depolarization-induced release of BDNF by neocortical pyramidal neurons promotes dendritic growth of surrounding inhibitory interneurons (Jin et al., 2003). Upregulation of pCREB expression also promotes morphological development of adult-generated granule cells (Fujioka et al., 2004).

Our results demonstrate that the maturation of newborn neurons is influenced by activity in their environment, but we cannot exclude intrinsic differences in neural stem cells derived from adults and neonates (Kruger et al., 2002). In support of a contribution by activity-dependent factors, maturation was altered after genetic deletion of GAD65. Neonatal GAD65 $5^{-1-}$ mice with reduced network activity (GDPs) had increased BrdU/EGFP co- labeling, consistent with a reduced rate of neuronal maturation. Although we cannot rule out alternative interpretations, including alterations in progenitor proliferation (Tozuka et al., 2005), such scenarios likewise support a role for network activity in the timing of granule cell development. Conversely, labeled granule cells in adult GAD65 ${ }^{-1-}$ mice had more mature morphology. It is unclear why EGFP continued to be expressed in newborn granule cells at an apparently more mature stage in adult $\mathrm{GAD}^{-1-}$ mice. However, this result is strikingly similar to the appearance of labeled cells after seizures, when their maturation and integration is dramatically accelerated (L. S. Overstreet-Wadiche, unpublished observation). Ongoing seizure activity in GAD65 $5^{-/-}$ mice (Kash et al., 1997) could underlie this similarity. Importantly, a qualitative shift in the maturation of newborn granule cells in neonate and adult GAD $65^{-/-}$mice mirrors the developmental shift in GABAergic actions in the surrounding network from depolarizing to hyperpolarizing, whereas GABA depolarizes newborn granule cells in both neonates and adults (Hollrigel et al., 1998; Esposito et al., 2005; Overstreet-Wadiche et al., 2005).

Activity-dependent modulation of granule cell maturation could result from direct GABAergic depolarization (Esposito et al., 2005; Overstreet-Wadiche et al., 2005; Tozuka et al., 2005; Wang et al., 2005; Ge et al., 2006), indirect depolarization via extracellular $\mathrm{K}^{+}$accumulation (Deisseroth et al., 2004), or by activity-dependent changes in the molecular environment of newborn cells. Our results support a contribution by activitydependent alterations in the environment. Comprehensive testing of each of these mechanisms will require selective manipulation of activity in newborn as well as more mature granule cells. Understanding the balance of the mechanisms regulating granule cell integration could provide insight into the functional integration of neural stem cells in the adult and diseased brain.

\section{References}

Adelsberger H, Garaschuk O, Konnerth A (2005) Calcium waves in resting newborn mice. Nat Neurosci 8:988-990.

Angevine Jr JB (1965) Time of neuron origin in the hippocampal region. An autoradiographic study in the mouse. Exp Neurol Suppl 2:1-70.

Asada H, Kawamura Y, Maruyama K, Kume H, Ding R, Ji FY, Kanbara N, Kuzume H, Sanbo M, Yagi T, Obata K (1996) Mice lacking the $65 \mathrm{kDa}$ isoform of glutamic acid decarboxylase (GAD65) maintain normal levels of GAD67 and GABA in their brains but are susceptible to seizures. Biochem Biophys Res Commun 229:891-895.

Ben-Ari Y (2001) Developing networks play a similar melody. Trends Neurosci 24:353-360.

Ben-Ari Y, Cherubini E, Corradetti R, Gaiarsa JL (1989) Giant synaptic potentials in immature rat CA3 hippocampal neurones. J Physiol (Lond) 416:303-325.

Brown JP, Couillard-Despres S, Cooper-Kuhn CM, Winkler J, Aigner L, Kuhn HG (2003) Transient expression of doublecortin during adul neurogenesis. J Comp Neurol 467:1-10.

Cohen-Cory S (2002) The developing synapse: construction and modulation of synaptic structures and circuits. Science 298:770-776.

Dayer AG, Ford AA, Cleaver KM, Yassaee M, Cameron HA (2003) Shortterm and long-term survival of new neurons in the rat dentate gyrus. J Comp Neurol 460:563-572.

Deisseroth K, Singla S, Toda H, Monje M, Palmer TD, Malenka RC (2004) Excitation neurogenesis coupling in adult neural stem/progenitor cells. Neuron 42:535-552.

Esposito MS, Piatti VC, Laplagne DA, Morgenstern NA, Ferrari CC, Pitossi FJ, Schinder AF (2005) Neuronal differentiation in the adult hippocampus recapitulates embryonic development. J Neurosci 25:10074-10086.

Fujioka T, Fujioka A, Duman RS (2004) Activation of cAMP signaling facilitates the morphological maturation of newborn neurons in adult hippocampus. J Neurosci 24:319-328.

Gaudilliere B, Konishi Y, de la Iglesia N, Yao G, Bonni A (2004) A CaMKIINeuroD signaling pathway specifies dendritic morphogenesis. Neuron 41:229-241. 
Ge S, Goh EL, Sailor KA, Kitabatake Y, Ming GL, Song H (2006) GABA regulates synaptic integration of newly generated neurons in the adult brain. Nature 439:589-593.

Goldman SA (2005) Neurology and the stem cell debate. Neurology 64:1675-1676.

Guillery RW, Herrup K (1997) Quantification without pontification: choosing a method for counting objects in sectioned tissues. J Comp Neurol 386:2-7.

Hensch TK, Fagiolini M, Mataga N, Stryker MP, Baekkeskov S, Kash SF (1998) Local GABA circuit control of experience-dependent plasticity in developing visual cortex. Science 282:1504-1508.

Hollrigel GS, Ross ST, Soltesz I (1998) Temporal patterns and depolarizing actions of spontaneous GABAA receptor activation in granule cells of the early postnatal dentate gyrus. J Neurophysiol 80:2340-2351.

Horch HW (2004) Local effects of BDNF on dendritic growth. Rev Neurosci 15:117-129.

Jin X, Hu H, Mathers PH, Agmon A (2003) Brain-derived neurotrophic factor mediates activity-dependent dendritic growth in nonpyramidal neocortical interneurons in developing organotypic cultures. J Neurosci 23:5662-5673.

Kash SF, Johnson RS, Tecott LH, Noebels JL, Mayfield RD, Hanahan D, Baekkeskov S (1997) Epilepsy in mice deficient in the 65-kDa isoform of glutamic acid decarboxylase. Proc Natl Acad Sci USA 94:14060-14065.

Katz LC, Shatz CJ (1996) Synaptic activity and the construction of cortical circuits. Science 274:1133-1138.

Kempermann G, Jessberger S, Steiner B, Kronenberg G (2004) Milestones of neuronal development in the adult hippocampus. Trends Neurosci 27:447-452.

Khazipov R, Sirota A, Leinekugel X, Holmes GL, Ben-Ari Y, Buzsaki G (2004) Early motor activity drives spindle bursts in the developing somatosensory cortex. Nature 432:758-761.

Kruger GM, Mosher JT, Bixby S, Joseph N, Iwashita T, Morrison SJ (2002) Neural crest stem cells persist in the adult gut but undergo changes in self-renewal, neuronal subtype potential, and factor responsiveness. Neuron 35:657-669.

Leinekugel X, Medina I, Khalilov I, Ben-Ari Y, Khazipov R (1997) $\mathrm{Ca}^{2+}$ oscillations mediated by the synergistic excitatory actions of GABA(A) and NMDA receptors in the neonatal hippocampus. Neuron 18:243-255.

Leinekugel X, Khalilov I, Ben-Ari, Khazipov R (1998) Giant depolarizing potentials: the septal pole of the hippocampus paces the activity of the developing intact septohippocampal complex in vitro. J Neurosci 18:6349-6357.

Leinekugel X, Khazipov R, Cannon R, Hirase H, Ben-Ari Y, Buzsaki G (2002) Correlated bursts of activity in the neonatal hippocampus in vivo. Science 296:2049-2052.

Liu X, Tilwalli S, Ye G, Lio PA, Pasternak JF, Trommer BL (2000) Morphologic and electrophysiologic maturation in developing dentate gyrus granule cells. Brain Res 856:202-212.

McAllister AK, Katz LC, Lo DC (1996) Neurotrophin regulation of cortical dendritic growth requires activity. Neuron 17:1057-1064.

Meijering M, Jacob M, Sarria JC, Steiner P, Hirling H, Unser M (2004) Design and validation of a tool for neurite tracing and analysis in fluorescence microscopy images cytometry. 58A:167-176.

Overstreet LS, Hentges ST, Bumaschny VF, de Souza FS, Smart JL, Santangelo AM, Low MJ, Westbrook GL, Rubinstein M (2004) A transgenic marker for newly born granule cells in dentate gyrus. J Neurosci 24:3251-3259.

Overstreet-Wadiche L, Bromberg DA, Bensen AL, Westbrook GL (2005) GABAergic signaling to newborn neurons in dentate gyrus. J Neurophysiol. 94:4528-4532.

Owens DF, Kriegstein AR (2002) Is there more to GABA than synaptic inhibition? Nat Rev Neurosci 9:715-727.

Pavlov I, Riekki R, Taira T (2004) Synergistic action of GABA-A and NMDA receptors in the induction of long-term depression in glutamatergic synapses in the newborn rat hippocampus. Eur J Neurosci 20:3019-3026.
Rakic P (2004) Immigration denied. Nature 427:685-686.

Rao MS, Hattiangady B, Abdel-Rahman A, Stanley DP, Shetty AK (2005) Newly born cells in the ageing dentate gyrus display normal migration, survival and neuronal fate choice but endure retarded early maturation. Eur J Neurosci 21:464-476.

Redmond L, Kashani AH, Ghosh A (2002) Calcium regulation of dendritic growth via CaM kinase IV and CREB-mediated transcription. Neuron 34:999-1010.

Saghatelyan A, Roux P, Migliore M, Rochefort C, Desmaisons D, Charneau P, Shepherd GM, Lledo PM (2005) Activity-dependent adjustments of the inhibitory network in the olfactory bulb following early postnatal deprivation. Neuron 46:103-116.

Schlessinger AR, Cowan WM, Gottlieb DI (1975) An autoradiographic study of the time of origin and the pattern of granule cell migration in the dentate gyrus of the rat. J Comp Neurol 159:149-175.

Seki T (2002) Expression patterns of immature neuronal markers PSANCAM, CRMP-4 and NeuroD in the hippocampus of young adult and aged rodents. J Neurosci Res 70:327-334.

Seri B, Garcia-Verdugo JM, McEwen BS, Alvarez-Buylla A (2001) Astrocytes give rise to new neurons in the adult mammalian hippocampus. J Neurosci 21:7153-7160.

Seri B, Garcia-Verdugo JM, Collado-Morente L, McEwen BS, Alvarez-Buylla A (2004) Cell types, lineage, and architecture of the germinal zone in the adult dentate gyrus. J Comp Neurol 478:359-378.

Shen Q, Goderie SK, Jin L, Karanth N, Sun Y, Abramova N, Vincent P, Pumiglia K, Temple S (2004) Endothelial cells stimulate self-renewal and expand neurogenesis of neural stem cells. Science 304:1338-1340.

Shieh PB, Hu SC, Bobb K, Timmusk T, Ghosh A (1998) Identification of a signaling pathway involved in calcium regulation of BDNF expression. Neuron 20:727-740.

Soghomonian JJ, Martin DL (1998) Two isoforms of glutamate decarboxylase: why? Trends Pharmacol Sci 19:500-505.

Song H-J, Stevens CF, Gage FH (2002) Astroglia induce neurogenesis from adult neural stem cells. Nature 417:39-44.

Staley KJ, Mody I (1992) Shunting of excitatory input to dentate gyrus granule cells by a depolarizing GABAA receptor-mediated postsynaptic conductance. J Neurophysiol 68:197-212.

Tao X, Finkbeiner S, Arnold DB, Shaywitz AJ, Greenberg ME (1998) $\mathrm{Ca}^{2+}$ influx regulates BDNF transcription by a CREB family transcription factor-dependent mechanism. Neuron 20:709-726.

Tian N, Petersen C, Kash S, Baekkeskov S, Copenhagen D, Nicoll R (1999) The role of the synthetic enzyme GAD65 in the control of neuronal gamma-aminobutyric acid release. Proc Natl Acad Sci USA 96:12911-12916.

Tozuka Y, Fukuda S, Namba T, Seki T, Hisatsune T (2005) GABAergic excitation promotes neuronal differentiation in adult hippocampal progenitor cells. Neuron 47:803-815.

van Praag H, Schinder AF, Christie BR, Toni N, Palmer TD, Gage FH (2002) Functional neurogenesis in the adult hippocampus. Nature 415:1030-1034.

Wang LP, Kempermann G, Kettenmann H (2005) A subpopulation of precursor cells in the mouse dentate gyrus receives synaptic GABAergic input. Mol Cell Neurosci 29:181-189.

Wong RO, Ghosh A (2002) Activity-dependent regulation of dendritic growth and patterning. Nat Rev Neurosci 3:803-812.

Ye GL, Yi S, Gamkrelidze G, Pasternak JF, Trommer BL (2005) AMPA and NMDA receptor-mediated currents in developing dentate gyrus granule cells. Brain Res Dev Brain Res 155:26-32.

Yu C, Power J, Barnea G, O’Donnell S, Brown HE, Osborne J, Axel R, Gogos JA (2004) Spontaneous neural activity is required for the establishment and maintenance of the olfactory sensory map. Neuron 42:553-566.

Zhao C, Teng EM, Summers Jr RG, Ming GL, Gage FH (2006) Distinct morphological stages of dentate granule neuron maturation in the adult mouse hippocampus. J Neurosci 26:3-11. 